Int. J. Electrochem. Sci., 12 (2017) 7597 - 7606

International Journal of

ELECTROCHEMICAL

SCIENCE

WwW.electrochemsci.org

\title{
Electrodeposition of Advanced SPR Thin Film for Ischemia Modified Albumin Levels Determination and Potential Hypertension Diagnosis
}

Xinghui Zhou ${ }^{\text {l\#, Zhaoqun Xiao }}{ }^{2 \#}$, Jianjun Lin $^{3 *}$, Danping Wang ${ }^{2}$, Xinhua Wang ${ }^{1}$, Weixing $\mathrm{Ji}^{l}$, Yao Zheng ${ }^{1}$, Haiming Jin $^{1}$, Yan Zhang ${ }^{1}$

${ }^{1}$ Department of examination, Taizhou Hospital of traditional Chinese and Western medicine, Taizhou 317523, China

${ }^{2}$ Department of Cardiology, Taizhou Hospital of traditional Chinese and Western medicine, Taizhou 317523, China

${ }^{3}$ Department of Examination, Ningbo Fourth Hospital, Ningbo 315700, China

\# These authors contributed equally to this work

*E-mail: jianjun_lin@foxmail.com

doi: $10.0964 / 2017.08 .21$

Received: 24 November 2016 / Accepted: 3 March 2017 / Published: 12 July 2017

In this work, a novel silver dendrite sensor, which was an enhancement based on the mixed selfassembled monolayers, was studied and employed to fabricate a surface plasmon resonace (SPR) immunosensor for the detection of ischemia modified albumin (IMA). The limit of the IMA detection was enhanced to $4.7 \mathrm{ng} / \mathrm{L}$ by the proposed silver dendrite, in comparison with the direct binding SPR measurement. Besides, no interferent was recognized, which could result in the false positive outcomes. These results indicated that a facile method without label could be supplied by the SPR biosensor with remarkable properties to improve the sensitivity of the assay for the further diagnose of hypertension.

Keywords: Biosensor; Surface plasmon resonance; Ischemia modified albumin; Hypertension; Silver dendrites

\section{$\underline{\text { FULL TEXT }}$}

(C) 2017 The Authors. Published by ESG (www.electrochemsci.org). This article is an open access article distributed under the terms and conditions of the Creative Commons Attribution license (http://creativecommons.org/licenses/by/4.0/). 